\title{
When does the Apple Fall from the Tree? Static Versus Dynamic Theories Predicting Intergenerational Transmission of Convictions
}

\author{
Marieke Van de Rakt • Stijn Ruiter • \\ Nan Dirk De Graaf • Paul Nieuwbeerta
}

Published online: 23 January 2010

(c) The Author(s) 2010. This article is published with open access at Springerlink.com

\begin{abstract}
Criminal behavior of parents substantially affects the criminal behavior of children. Little is known, however, about how crime is transmitted from one generation to the next. In order to test two possible explanations against each other, we pose the question whether the timing of the criminal acts of fathers is important for children's chances of committing crime. Static theories predict that it is the number of delinquent acts performed by fathers that is important, and that the particular timing does not affect the child's chance of committing crime. Dynamic theories state that the timing is important, and children have a greater chance of committing crime in the period after fathers have committed delinquent acts. Results show that the total number of convictions of a father is indeed very important, but also the exact timing is key to understanding intergenerational transmission of crime. In the year a father is convicted the chance his child is also convicted increases substantially and it decays in subsequent years. This decay takes longer the more crimes father has committed. Our results show that some of the assumptions of the static theories at least need to be adjusted.
\end{abstract}

Keywords Intergenerational transmission - Convictions - The Netherlands · Timing $\cdot$ Life course criminology $\cdot$ Static versus dynamic theories

\footnotetext{
M. Van de Rakt ( $\square)$

Department of Sociology, Radboud University Nijmegen, Nijmegen, The Netherlands e-mail: m.vanderakt@maw.ru.nl

S. Ruiter

Netherlands Institute for the Study of Crime and Law Enforcement (NSCR), Amsterdam,

The Netherlands

e-mail: sruiter@nscr.nl

N. D. De Graaf

Nuffield College, Oxford, UK

P. Nieuwbeerta

Department of Criminology, Leiden University, Leiden, The Netherlands
} 


\section{Introduction}

Numerous studies show a substantial influence of parents' criminal behavior on the criminal behavior of their children (e.g., Rowe and Farrington 1997; Van de Rakt et al. 2008; Thornberry et al. 2003). Most of these studies are limited in the sense that they only focus on correlations between numbers of convictions of fathers and children, and as such, they do not deal with the way parental influence develops over the course of children's lives. In this study, we explicitly set out to do so. We examine the influence of parental criminal behavior on the development of criminal careers of children. We do so by answering the question to what extent intergenerational transmission of criminal tendencies is dependent upon the timing of criminal acts of fathers. By 'timing of criminal acts', we refer to the age of children when their father committed criminal acts. This line of inquiry enables us to answer questions like: 'Does a child only have a greater chance of a criminal conviction if the father commits a crime before the child was born or is this chance also increased if the father commits a crime when the child is an adolescent or even an adult?'

In the last two decades we have witnessed a massive increase in studies that investigate the criminal behavior of individuals over the life course (e.g., Piquero et al. 2003; Blokland and Nieuwbeerta 2005). The main part of this research focuses on intragenerational developments in criminal behavior-i.e. the trajectories of criminal behavior over the life span of individuals (e.g., Bushway et al. 1999; Laub and Sampson 2003; Piquero et al. 2003). A much smaller (but growing) tradition within the developmental and life course criminology considers intergenerational developments-i.e. the similarities and differences between the criminal behavior of parents and their children (Rowe and Farrington 1997; Bijleveld and Farrington 2009). In this paper, we will connect the research tradition of intragenerational comparisons with the tradition of the intergenerational transmission both theoretically and methodologically by asking the question how parental criminal behavior influences the development of criminal behavior of children over the course of their lives. Our results will give insight into the transmission of the chance of convictions over the entire life span.

Over the past decades, life course and developmental criminology has shown much debate about the question whether the tendency to criminal behavior is stable over the life course or not (e.g., Paternoster et al. 1997; Bushway et al. 1999). In this regard, we can differentiate between two paradigms and derive (partly) conflicting hypotheses from each about the influence of the timing of criminal behavior of fathers on the development of criminal behavior of their children (Nagin and Paternoster 1991, 2000).

One group of criminologists assumes that people differ in their propensity to commit crime. Theories in this tradition are often referred to as static theories. The literature often also refers to this position as 'population heterogeneity' (Nagin and Paternoster 1991) or 'persistent heterogeneity' (Piquero et al. 2003). According to this view, each individual has a certain chance to commit crime. Individual differences could be due to personality traits and biological causes (Wilson and Hernstein 1985) and/or to differences in upbringing as predicted by the self-control theory of Gottfredson and Hirschi (1990). The self-control theory states that criminal parents lack the necessary self-control and skills to adequately raise and educate their children, resulting in children who also grow up with little selfcontrol and who have a high chance of committing crime. According to static theories, the timing of criminal behavior of fathers is in itself unimportant, because only circumstances experienced during the early childhood would influence one's criminal behavior. Selfcontrol theory argues that the relationship between the number of criminal acts of a father 
and those of his children is spurious, as it could be explained by the transmission of low self-control. Fathers with little self-control commit a lot of crime and as a result of their low level of self-control they also are inadequate child-raisers. Consequently, their children grow up having little self-control and committing crime too.

Another group of criminologists holds that the tendency to commit crime changes during the life course. Explanations within this tradition are referred to as dynamic theories. This position is often also referred to as 'state dependence' (Nagin and Paternoster 1991), meaning that life circumstances influence one's chance of committing crime and that there exists a causal relation between past and future criminal behavior. Conventional behavior like graduating from school and entering the labor market would diminish one's chances of committing crime, while having delinquent friends would cause an increase of the chance of criminal activity (Sampson and Laub 1990). Dynamic theories assume that the influence of parents on the criminal behavior of children extends beyond early childhood.

The current study tests the extent to which heterogeneity and state dependence succeed in explaining the intergenerational transmission of criminal behavior. We make use of a unique large-scale dataset to analyze the complete life courses of fathers and their children (aging between 12 and 39), investigating the timing of fathers' convictions and the transmission of criminal tendencies to their offspring. This design enables us to test and compare explanations from both static and dynamic theories.

\section{Previous Research}

Most previous studies investigating the intergenerational transmission of criminal behavior focus on correlations between numbers of convictions of fathers and sons (e.g., Kaplan and Tolle 2006; Farrington et al. 2001; Thornberry et al. 2003). Relatively little is known, however, about the mechanisms that cause the intergenerational transmission (but see: Bijleveld and Farrington 2009). Few studies pay attention to the development of criminal careers and even fewer to the exact point in time when fathers were (still) criminally active.

Nevertheless, several panel studies did reveal important insights into the association between parental criminal behavior and that of their offspring. Results from the Chicago Youth Development Study, (Gorman-Smith et al. 1998) show that persistent delinquents are more likely to originate from families that display deviant conduct. In the Pittsburgh Youth Study, Farrington et al. (2001) note a similar pattern. These results show that fathers are the most important relative in predicting the criminal behavior of an individual. Sampson and Laub (1993) also reveal a substantial association between father's criminal behavior and that of their offspring in their analyses of the Glueck data. This association appears to be mediated by upbringing and supervision. The Rochester Youth Development Study (RYDS), executed by Thornberry (2005), investigates the influence of antisocial behavior of parents on the aggressive behavior of their young children. For fathers a direct effect of delinquency on the behavior of their young children exists. Also, a direct effect of parents' delinquency on the behavior of their children is revealed; for mothers, however, this relation is mediated through the parenting strategy she uses (Thornberry et al. 2003). In a more recent study, Thornberry et al. (2009) again show that parental antisocial behavior is related to that of their children as long as the parents have frequent contact with their children.

One study is responsible for most of the findings on intergenerational similarities in criminal behavior: the Cambridge Study in Delinquent Development (CSDD). Results 
from that study show a .43 correlation between the number of convictions of fathers and that of their sons (Rowe and Farrington 1997). Results also show that the timing of convictions of parents barely influences the intergenerational transmission of criminal behavior. Parents who committed their final criminal act before the birth of their children, had about the same influence on the chance of their children committing crime as parents with a conviction after the child's birth (Smith and Farrington 2004; Farrington et al. 1998).

The Criminal Career and Life Course Study (CCLS) is the largest Dutch investigation of criminal life courses and intergenerational transmission of criminal tendencies. Using the Dutch data, Van de Rakt et al. (2009) find a correlation between number of convictions of fathers and that of their sons of about .25 (and between fathers and daughters of .20). Another study using the CCLS-data (Van de Rakt et al. 2008) analyses the development of criminal life courses of children of fathers with very different criminal histories. Results show that children whose fathers had an extensive criminal record had different criminal life courses from children with noncriminal fathers. Nevertheless, both groups of children show the typical age-crime curve. That is, they have a relatively low number of convictions in childhood, a rapid rise during adolescence, a peak in the mid-twenties and finally a slow decline thereafter. The differences between the groups of children are thus foremost differences in the height of the age-crime curves and not so much in the shapes of these curves.

Summarizing, the results of these earlier studies indicate a moderately strong association between the criminal behavior of parents and the behavior of their children. The designs of these earlier studies (for an overview, see Van de Rakt et al. (2008)), however, have numerous limitations. First, these studies use relatively small datasets, which precludes the use of more advanced statistical testing. Second, most studies employ very limited follow-up periods and neglect analysis of the effects of parents' criminal behavior on the behavior of adult offspring. Finally and most importantly, most previous research, including that using the CCLS data, focuses only on cross-sectional relations and fails to analyze the development of criminal behavior into adulthood. We will improve upon all of these drawbacks.

\section{Theoretical Framework}

This study on the effects of timing of parental criminal behavior tests explanations from two traditions within life course and developmental criminology. Our first set of hypotheses about the influence of timing of the delinquent acts of fathers is derived from static theories. Secondly, a set of parallel hypotheses about the influence of timing is then derived from dynamic theories. We stress that while we test the explicit hypotheses in this study, the underlying assumptions and mechanisms remain, due to data limitations, largely implicit.

\section{Static Theories}

Strict versions of static theories assert that population heterogeneity is the only explanation for differences in people's likelihood of committing crime. These theories assume that this likelihood (or propensity) to commit crime is not causally influenced by the level of delinquency of the father. The empirical relationship is regarded as spurious. 
Several static theories exist. They have in common their stress of the impact of personal characteristics, but they differ in the type of characteristics that they focus on, e.g., biological or psychological factors. Wilson and Hernstein (1985), for example, propose that criminal behavior is caused by biological personality traits and constitutional factors. They explicitly mention criminal behavior of parents as a risk factor for the development of crime-favorable personality traits and constitutions. ${ }^{1}$

Another example of a static theory, and probably the most tested in criminology, is Gottfredson and Hirschi's (1990) self-control theory, which holds that criminal behavior is entirely caused by a lack of self-control. Their theory assumes that people who have little self-control display more (often) risk-taking behavior, are short-sighted, and aim at immediate gratification.

Gottfredson and Hirschi's self-control theory assumes that inadequate parenting in early childhood is deemed responsible for a lack of self-control and consequently for all sorts of unadjusted behavior, including crime. Children whose parents do not consistently monitor, correct and punish their behavior are more likely to have low levels of self-control. According to Gottfredson and Hirschi, no parents encourage their children to commit crimes, irrespective of their own criminal history. However, as criminal parents themselves have little self-control, their own behavior will be oriented towards immediate gain, and they are unlikely to pass on the skills of self-discipline and delayed gratification to their children. They will furthermore be less likely to recognize criminal behavior in their children and will correct and punish less consistently, resulting in children with little selfcontrol. Parents with little self-control (and many convictions) thus will have children with little self-control (and many convictions) due to their inadequate parenting. The window of development of self-control is considered to be rather short. Gottfredson and Hirschi $(1990 ; 109)$ state that 'the level of self-control distinguishes offenders from non-offenders and the degree of its presence can be established before criminal acts have been committed'. An explicit age is not mentioned in their work, although preadolescence, in the early years of life and early adolescence are mentioned. In our paper, we assume that the level of self-control remains stable from the age of $12 .^{2,3}$

Summarizing, from static theories it can be derived that as a father commits more delinquent acts, the more likely his children will commit more delinquent acts as well. According to Gottfredson and Hirschi, self-control remains stable after childhood, and persons with little self-control have a higher chance of committing crime under all conditions, in every phase of their lives. According to the view of Wilson and Hernstein (1985) the personality traits inherited and formed early in life will be transmitted from (criminal) parents to their children. So, according to these static theories, there will be heterogeneity between persons, but there can be no changes within persons. This leads to the following hypothesis: H1: As fathers commit more criminal acts over the course of their lives, their

\footnotetext{
${ }^{1}$ Population heterogeneity could also come about because of biological (genetic) factors. However, that does not necessarily mean that biological explanations are entirely static. The influence of a genetic predisposition could change over the life course.

2 Nagin and Paternoster (2000) point to the fact that Gottfredson and Hirschi do not refute the possibility of socialization after early childhood altogether. They do, however, believe that self-control is a time-stable trait and that the rate at which socialization takes place after early childhood will be about the same for everyone. Although we are aware of this controversy, we will assume self-control to be a time-stable characteristic.

3 Nagin and Paternoster (2000) state that the age until self-control can be formed is approximately 8 or 10. We will take 12 in order to be entirely sure that all parenting influences (according to self-control theory) will have taken place.
} 
children will have a greater chance of committing crime, regardless the timing of father's crimes (father's crime hypothesis).

Since the relationship between father's criminal career and that of their children is assumed to be spurious, static theories also assume that the point in time when a father commits his crimes in no way influences the chance his child also commits crime. The number of criminal acts a father commits is due entirely to his personal characteristics that are transmitted to his children and that will subsequently lead to higher number of offences of his children. Whether a father commits his crimes before his children were born or when they were committed during their adolescence or even when they reach adulthood, it should make no difference. This suggests the following hypothesis: H2: The timing of father's crimes does not affect the way children's criminal careers develop (static hypothesis).

\section{Dynamic Theories}

In direct contrast to static theories, dynamic theories assume that individuals' propensity to commit crimes can change during the life course. In dynamic theories, state dependence is very important, although it is important to stress that this does not mean that there is no room for population heterogeneity. Above and beyond persistent individual differences, life events are assumed to have effect on people's lives. Previous research shows that both population heterogeneity and life changes are important (Nagin and Paternoster 2000). In most studies, the possible 'positive' effects of bonds with parents, institutions and spouses are investigated (Piquero et al. 2003). In this paper, however, we will analyze whether 'negative' (criminal) behavior of fathers influences one's criminal career, even if fathers commit their crimes after early childhood. In this study we apply two dynamic theories: differential association theory (Sutherland et al. 1992) and the age-graded theory of informal social control (Sampson and Laub 1990). Due to data limitations we will not be able to test the specific mechanisms of either theory. We present these mechanisms mainly for illustrative purposes; other mechanisms could well account for the same hypothesis. However, we will be able to test whether dynamic factors are able to explain the influence of paternal criminal behavior on the development of criminal careers of children.

Differential association theory assumes that criminal behavior is taught in the same manner as normal (accepted) behavior. Learning criminal behavior would for a large part take place in intimate personal groups, such as the family. Not only the techniques individuals must master to commit crime can be taught, but also motives, values and attitudes towards crime can be learned. Association with delinquents then leads to a higher chance of learning and committing crime (e.g., Sutherland et al. 1992; Akers and Jensen 2003). Association with criminal parents, who are role models for their children, is especially influential in determining children's criminal behavior.

In this study we test whether the criminal acts of fathers could induce learning effects in their children. Although we are not able to test the learning process itself, we can derive predictions about the outcomes of possible learning mechanisms. We illustrate our outcome-hypotheses with examples of how learning or imitation could take place. Children, when confronted with the criminal behavior of their father (e.g., because they witness the actual behavior or the father tells them about it), could store this information in their memory. In this way children acquire the techniques, knowledge and values needed to commit crime. Moreover, these children might come to view criminal behavior as normal and even desirable. From this follows that children would have a greater chance of committing crime after their father has committed a criminal act. This so-called 'learning 
effect' suggests the following hypothesis: H3: After a father commits a delinquent act, his children will then have a greater chance of committing crime as well (learning hypothesis).

If a father commits several subsequent crimes, the learning effect can of course occur repeatedly. With every additional crime, the children could again be confronted with criminal behavior. Subsequent confrontations like the first could be direct, for instance when the children are also present at the crime scene, or indirect, if their father tells them about his criminal acts. Again, we would like to emphasize that these learning-mechanisms remain speculative. Subsequent confrontations could remind the child of the previous delinquent acts. The (implicit) norms are reinforced. The knowledge and techniques learned from the previous delinquent acts are repeated. Also, father's deviant behavior could come to appear a bit more normal to the child. We expect that with every additional delinquent act of the father the learning effect increases. Sampson and Laub (1990) speak of 'cumulative disadvantages' in this context. Repeated exposure to deviant behavior could feed the child's idea that criminal behavior is normal. We refer to this effect as the 'cumulative learning effect' and formulate the following hypothesis: H4: With every additional delinquent act of the father, his children will have an increasingly larger chance of committing delinquent acts thereafter (cumulative learning hypothesis).

We assume that the learning effect diminishes over time, because when time passes without any new crimes committed by the father, the memory could become less vivid. Knowledge about how best to commit crime might fade. Norms and values accompanying a criminal lifestyle are no longer reinforced. Gradually, the child's chance of committing crime is expected to diminish. Insights from psychology and biology show that experiences from the past subside if they are no longer reinforced (Wixted and Ebbesen 1991; Ebbinghaus 1913). We explicitly test whether such diminishment occurs. A plausible mechanism for diminishment would be that the child's memory of father's criminal behavior becomes less and less vivid when time since father's last crime passes. As the period of time since father's last criminal act lengthens, the increased chance of the child committing a delinquent act (as predicted in H3) will gradually be reduced. We call this the 'decay effect' and associate it with the following hypothesis: H5: The more time that passes after a father has committed a crime, the more the initially increased chance of a child committing a crime (as predicted by the learning effect) diminishes (decay hypothesis).

Psychological learning theories (e.g., Wixted and Ebbesen 1991) show that memory fades less rapidly after repeated confrontation. Forgetting a confrontation with father's criminal behavior then would take more time if a father commits more criminal acts. Criminological theories refer to this as a 'reinforcement effect' (e.g., Akers and Jensen 2003), suggesting our next hypothesis: H6: With every additional delinquent act of the father the over-time diminishment of his child's chance of committing crime is slower (in other words, the decay effect will elapse more slowly) (reinforcement hypothesis).

\section{Additional Hypotheses}

Insights from the age-graded theory of informal social control (Sampson and Laub 1990) help us to predict in which period in life fathers have greatest influence on the (criminal) behavior of their children. We derive additional predictions that lead to extra tests of the developmental criminological theories presented above. The age-graded theory of informal social control states that certain changes in the life course modify one's probability of committing crime. That is, different bonds and circumstances play a role in different periods of people's lives. During childhood and adolescence, bonds with parents and 
success in school are most important. After that, bonds with one's own family (through marriage and having children) and success in the labor market become more important.

We assume, based on the age-graded theory of informal social control, that children's learning of criminal behavior from their parents takes place especially in the periods in which the bond with their parents is strongest. This translates to a high parent-child transmission of criminal behavior and criminal techniques in the period before adulthood, as we assume that the learning effect is larger in this period than in the period after adolescence. We also expect children in adolescence to forget confrontations with parents' criminal behavior less rapidly than during adulthood. Both expectations lead us to propose the next hypothesis: H7: During adolescence the learning effect is especially large, while the decay effect is especially small (adolescence hypothesis).

A precondition for learning criminal behavior from fathers is of course fathers' presence in the lives of their children. Many children, however, experience a divorce of their parents (Fischer 2004). After a divorce, most children live with their mother (Fischer et al. 2005). The father might still play a role in the lives of the children, but he is usually no longer present in everyday life. Children of divorced parents would then (on average) be confronted less with the criminal activities of their father than children whose parents are still married. Thornberry et al. (2009) demonstrate that only fathers who are frequently in contact with their children transmit antisocial behavior. From this follows our expectation that the learning effect is probably smaller for children whose parents are divorced. We also expect children's memory of their father's criminal behavior to fade more rapidly when their father is no longer living in the same household. This leads to our final hypothesis: H8: The learning effect is smaller after a parental divorce, while the decay effect is larger (divorce hypothesis).

Previous research clearly shows that disruptions in families can cause problematic behavior among children. However, giving a bad example also leads to criminality among offspring. In fact, the salutary effects of being raised by two married parents depend on the behavior that parents display (e.g., Jaffee et al. 2003; Blazei et al. 2008). The question remains whether children whose fathers commit crime are less prone to become criminal themselves if their fathers are out of the picture after a divorce.

\section{Data}

In order to answer our research question empirically we analyze data from the Criminal Career and Life Course Study (CCLS). The CCLS was established by the Netherlands Institute for the Study of Crime and Law Enforcement (NSCR). It uses a representative sample of $4 \%$ of all criminal offence cases tried in the Netherlands in 1977 (the project builds on Nieuwbeerta and Blokland 2003; Blokland 2005). The research subjects of the original CCLS study from 1977 number 5,164, of whom 4,271 are men. Extracts from the general documentation files of the Criminal Record Office ('rap sheets') are used to reconstruct these research subjects' entire criminal careers. In the Netherlands, a person can be convicted for criminal behavior from the age of 12. The data therefore contain information on both adult and juvenile offences (committed from the age of 12 and older). Only information on offences that led to some type of judicial action is used, thereby excluding noncriminal offences (e.g., traffic and economic offences). The criminal acts analyzed in this paper are thus all criminal law offences, ranging from simple theft (e.g., shoplifting) to manslaughter and murder. This information is supplemented by population registration data (e.g., dates of marriage, birth of children and deaths). 
Table 1 Descriptive statistics

\begin{tabular}{|c|c|c|c|}
\hline & Mean & Range & $N$ \\
\hline \multicolumn{4}{|l|}{ Time-constant variables } \\
\hline Sex $($ female $=1)$ & .50 & $0 / 1$ & 6,921 \\
\hline Total number of criminal convictions father over the entire life course & 10.24 & $1-186$ & 6,921 \\
\hline Number of children within the family & 3.21 & $1-11$ & 6,921 \\
\hline \multicolumn{4}{|l|}{ Time-varying variables } \\
\hline Age & 22.63 & $12-39$ & 123,630 \\
\hline Number of criminal convictions father after child is age 12 & 3.86 & $0-163$ & 123,630 \\
\hline Parental divorce & .47 & $0 / 1$ & 123,630 \\
\hline Deceased father & .09 & $0 / 1$ & 123,630 \\
\hline \multicolumn{4}{|l|}{ Dependent variable } \\
\hline Criminal conviction in a certain year & .05 & $0 / 1$ & 123,630 \\
\hline
\end{tabular}

This study, in which intergenerational transmission is central, employs the male research subjects of the original CCLS study and expands these data using the penal records of their children ('CCLS children', Van de Rakt and Nieuwbeerta 2005). Population registration data show that the 4,271 men had 6,921 children older than age 12 in 2003 (the end of our observation period). Again, extracts from the general documentation files were used to reconstruct the entire criminal careers of these 6,921 children. For a more complete description of the data we refer to Van de Rakt et al. (2008).

Table 1 presents some descriptive statistics of the variables that are used in this study. It shows that about half of the children are male. The total number of criminal convictions of fathers over their entire life course varies from 1 to 186, clearly an indication of a large variety of criminal fathers. The average number of children within a family is 3.21 and these children are on average 22.63 years old. After the 12th birthday of the children the fathers were 3.86 times convicted on average. This shows that most of the criminal acts were committed before the children reached the age of 12 . About half of the children in our data experienced a divorce and about $10 \%$ were confronted with the death of their father. Divorce and death rates are much higher in this (criminal) group than among children without criminal fathers (Van de Rakt et al. 2006). On average, the children get convicted in $5 \%$ of all years.

\section{Methodology}

We test our hypotheses by means of event history analysis with repeated events. Our dataset contains a record for every child for every year after the age of 12 . When a child died in a specific year, no records for subsequent years are included. The dataset contains 123,630 person-years for 6,921 individuals (i.e. children). For every year we recorded whether a child was convicted of one or more crimes. Employing the NLMIXED procedure in SAS, we estimate logistic regression models for the chance of one or more convictions in a year. ${ }^{4}$ This procedure enables us to model a nonlinear decay function. In addition, it allows us to account for the fact that our observations are not independent, as

\footnotetext{
${ }^{4}$ We choose a logistic model instead of a Poisson or negative binomial model, because the number of years in which individuals are convicted more than once are negligible.
} 
we study numerous years for the same person. We account for this nested structure of the data (person-years within persons) by means of hierarchical analysis. As we know of no software that allows for estimating nonlinear decay functions, while simultaneously accounting for more than 2 levels of nesting, we cannot correct for the fact that siblings are nested within fathers. Nevertheless, we do not expect this to interfere with our conclusions. $^{5}$

We estimate four hierarchical logistic regression models. The first model includes the control variables and the static effect of the total number of convictions of the father (testing $\mathrm{H} 1$ and $\mathrm{H} 2$ ). Our second model adds the learning effect and the decay effect (testing $\mathrm{H} 3$ and $\mathrm{H} 5$ ). In the third model we add the cumulative learning effect and the reinforcement effect (testing H4 and H6). Finally, the fourth model includes the interaction effects of divorce and adolescence (testing $\mathrm{H} 7$ and $\mathrm{H} 8$ ).

Next, we describe for each of the four models how we test our hypothesized effects.

\section{Model 1}

In Model 1 we start with a number of control variables. First, we estimate the effect of age. The chance of a conviction rapidly increases during adolescence, peaks in the early twenties and then gradually decreases (e.g., Gottfredson and Hirschi 1990; Moffitt 1993). Following Blossfeld and Huinink (1991), we therefore model the age effect with two log variables. The first log variable indicates the gradual decrease after the peak, while the second captures the initial rise. We choose this way of modeling over the traditional method with a quadratic term for age because the age-crime curve is known not to be a symmetric parabola. Blossfeld and Huinink's method does not assume symmetry and requires the same degrees of freedom. Second, we estimate the effect of having a deceased father, for which 0 indicates that the father is still alive in a specific year and 1 means the father has died. From the literature we know that children whose fathers died have a larger chance of committing crime (e.g., Harper and McLanahan 2004). Of course, the past criminal behavior of a father who has died can still affect his children's chances of committing crime. Third, we estimate the influence of parental divorce, for which 0 indicates that the parents were still married in a specific year and 1 means the parents had separated (or were never married). We control for divorce because the literature shows that men with criminal tendencies have larger chances of divorce (Van de Rakt et al. 2008) and because children of divorced parents are more likely to commit crime (McLanahan and Sandefur 1994). Fourth, we take into account the number of children within a family. According to the literature, criminal fathers have more children on average (Van de Rakt et al. 2006), and it seems reasonable to expect that children within large families experience less parental control than children in smaller families (Gottfredson and Hirschi 1990). Finally, we take into account sex, with 1 indicating the research subject is a woman. The literature shows large differences between men and women in the tendencies to commit criminal acts (e.g., Van de Rakt et al. 2008).

The key parameter we estimate in Model 1 is the effect of the total number of criminal convictions of the father. Static theories suppose that individuals differ in their tendency to commit crime and that these differences are caused by differences in self-control among

\footnotetext{
5 We estimated Model 1 (in which no nonlinear decay function is included) using the lme4 package in $\mathrm{R}$ with 2 levels (person-years nested within persons) as well as 3 levels (person-years nested within persons nested within fathers). The differences in estimated effects and standard errors were minimal and did not lead to other conclusions.
} 
fathers. In order to account as much as possible for father's level of self-control and to test father's crime hypothesis (H1), we count the total number of criminal convictions of fathers. This is our best (though indirect) measure of self-control of the father. We assume that the difference between fathers who commit 2 or 3 crimes is more important than the difference between those committing 20 or 21 criminal acts. We therefore use a $\log$ transformation of the total number of father's criminal convictions.

\section{Model 2}

In Model 2 we estimate, in addition to the parameters of Model 1, the initial learning effect and the decay effect. We assume that the criminal learning process begins when a father is convicted for the first crime after the child has reached the age of $12 .{ }^{6}$ Before that, we model no influence of learning effects. Our 'learning effect hypothesis' (H3) implies that a child's chance of conviction rises in the year the father is convicted for his crime(s). This learning effect is denoted by $\beta_{1}$ in Eq. 1 .

If a father does not commit any crimes in subsequent years, the decay hypothesis (H5) implies that the effect of the first confrontation with father's criminal behavior declines. That is, with every additional year $(T)$ that goes by, the influence decreases. After a certain amount of time a child's chance of conviction is indistinguishable from the original probability. Insights from psychology and biology show that forgetting information or skills usually follows an exponential decay process (Wixted and Ebbesen 1991). We therefore model our decay effect $\left(\beta_{2}\right)$ by way of an exponential function. ${ }^{7}$

The equation with the learning effect and the decay effect reads as follows:

$$
\ln \left(\frac{P}{1-P}\right)=\beta_{1} \times \exp \left(-\frac{(T+1)}{\beta_{2}}\right)+B \times X
$$

In Eq. $1, \beta_{1}$ denotes the learning effect, $\beta_{2}$ captures the decay effect and $T$ is the number of years since a father was last convicted. We use $T+1$, because we expect the influence of father's criminal behavior to be realized right away and not a year after the criminal conviction. $B$ denotes the parameter vector belonging to $X$, the matrix of all other covariates including an intercept.

As hypothesized (H3), we expect a positive learning effect $\left(\beta_{1}\right)$. A larger value for this learning parameter means that the chance of conviction in a certain year is larger. If H5 holds, we also expect a positive decay parameter $\left(\beta_{2}\right)$. That is, the chance of conviction decreases as the years pass after father's last conviction. A larger decay parameter would imply a slower decay. That is, the chance of conviction remains higher for a longer period of time when the decay parameter is larger.

\footnotetext{
${ }^{6}$ Of course this assumption is a simplification of the learning process. Learning could also take place before the age of 12, but we cannot correctly model that learning process due to the nature of our data. However, we assume that criminal learning requires a level of consciousness that is lacking among most children under the age of 12 .

7 Additional analyses (not shown) show that the model with the exponential decay function fits the data better than a model with a linear decay function. Besides, compared to a linear function, the exponential decay function offers the advantage of asymptotically approaching the point of departure.
} 


\section{Model 3}

Model 3 adds parameters to test whether we find evidence for the cumulative learning effect (H4) and the reinforcement effect (H6). These effects come into play only when a father has been convicted multiple times. For his second conviction, we expect a cumulative effect $\left(\beta_{3}\right)$ on top of the original learning effect $\left(\beta_{1}\right)$.

The speed of the decay slows down, according to the theory of Ebbinghaus (1913), every time a person is exposed to the relevant stimulus (in this case, a criminal conviction of the father). We thus expect it to take longer for the chance of a child's conviction to settle at its original value when a father has committed multiple criminal acts. Both the increase in the chance of criminal learning and the decrease of the speed of the decay thus depend upon the number of criminal convictions of the father. Because we again assume diminishing effects (as in our test of father's crime hypothesis (H1)), we include the log transformation of father's number of criminal convictions after the child reached age $12 .{ }^{8}$ Model 3, with learning effects, decay effect and reinforcement effect is shown in Eq. 2:

$$
\ln \left(\frac{P}{1-P}\right)=\left(\beta_{1}+\beta_{3} \times \ln (N)\right) \times \exp \left(-\frac{(T+1)}{\left(\beta_{2}+\beta_{4} \times \ln (N)\right)}\right)+B \times X
$$

In Eq. $2, \beta_{1}$ again denotes the learning effect and $\beta_{2}$ the decay effect. $\beta_{3}$ denotes the cumulative learning effect and $\beta_{4}$ the reinforcement effect. $T$ again signifies the number of years elapsed since father's last conviction. $N$ denotes the number of times a father was convicted after the child reached the age of $12 . B$ again is the parameter vector belonging to $X$, the matrix of all other covariates including an intercept. A positive cumulative learning effect $\left(\beta_{3}\right)$ would imply an stronger increase of the chance of a child's conviction with every additional criminal conviction of the father. If fathers have a more extensive criminal record, the decay elapses slower and the reinforcement effect $\left(\beta_{4}\right)$ increases. We thus expect $\beta_{4}$ to have a positive value.

\section{Model 4}

In our additional predictions we formulated two hypotheses. First, we suggested that the initial learning effect is larger and the decay effect smaller in years in which parents are (still) together instead of divorced. We therefore estimate an additional learning effect for all years that parents are divorced. Furthermore, we test whether an accelerated decay takes place in the years parents are divorced. Second, we hypothesized that the learning effect is larger in the years children are in adolescence (ages 12 through 19). Decay would be slower in these years. We therefore take a second set of additional variables for the learning effect and the decay effect. Model 4 includes these additional effects and is shown in Eq. 3:

$$
\begin{aligned}
\ln \left(\frac{P}{1-P}\right)= & \left(\beta_{1}+\beta_{3} \times \ln (N)+\beta_{5} \times D+\beta_{6} \times \operatorname{Ad}\right) \\
& \times \exp \left(-\frac{(T+1)}{\left(\beta_{2}+\beta_{4} \times \ln (N)+\beta_{7} \times D+\beta_{8} \times \mathrm{Ad}\right)}\right)+B \times X
\end{aligned}
$$

In Eq. 3, $\beta_{5}$ and $\beta_{6}$ denote the additional learning effects of divorce $(D)$ and adolescence (Ad) and $\beta_{7}$ and $\beta_{8}$ signify the additional decay effects of divorce and adolescence.

\footnotetext{
8 This log transformation again showed a better fit to the data than a linear function.
} 
Table 2 Discrete-time event history models of criminal conviction in a certain year $\left(N_{\text {person }}=6,921\right.$; $\left.N_{\text {person-years }}=123,630\right)$

\begin{tabular}{|c|c|c|c|c|c|c|c|c|}
\hline & \multicolumn{2}{|l|}{ Model 1} & \multicolumn{2}{|l|}{ Model 2} & \multicolumn{2}{|l|}{ Model 3} & \multicolumn{2}{|l|}{ Model 4} \\
\hline & $b$ & (SE) & $b$ & (SE) & $b$ & (SE) & $b$ & (SE) \\
\hline Intercept & $-9.40 * * *$ & $(.20)$ & $-9.30 * * *$ & $(.30)$ & $-9.30 * * *$ & $(.40)$ & $-9.37 * * *$ & $(.20)$ \\
\hline $\log ($ age-11) & $1.18^{* * *}$ & $(.04)$ & $1.19 * * *$ & $(.04)$ & $1.20 * * *$ & $(.04)$ & $1.19^{* * *}$ & $(.04)$ \\
\hline $\log (40$-age $)$ & $.80^{* * *}$ & $(.04)$ & $.75 * * *$ & $(.04)$ & $.77 * * *$ & $(.04)$ & $.76^{* * *}$ & $(.04)$ \\
\hline Sex $($ female $=1)$ & $-2.18 * * *$ & $(.08)$ & $-2.20^{* * *}$ & $(.08)$ & $-2.18 * * *$ & $(.08)$ & $-2.18 * * *$ & $(.08)$ \\
\hline Parental divorce & $.34 * * *$ & $(.06)$ & $.32 * * *$ & $(.06)$ & $.32 * * *$ & $(.06)$ & $.48 * * *$ & $(.07)$ \\
\hline Deceased father & .05 & $(.07)$ & .13 & $(.08)$ & .11 & $(.08)$ & .11 & (.07) \\
\hline $\begin{array}{l}\text { Number of children } \\
\text { within the family }\end{array}$ & .31 & $(2.10)$ & -.72 & $(2.08)$ & -.08 & (2.06) & -.09 & $(2.06)$ \\
\hline $\begin{array}{l}\text { Log (total number of } \\
\text { criminal convictions } \\
\text { father) }\end{array}$ & $.49^{* * *}$ & $(.03)$ & $.40 * * *$ & $(.04)$ & $.41 * * *$ & $(.04)$ & $.40^{* * * *}$ & (.04) \\
\hline Learning effect $\left(\beta_{1}\right)$ & & & $.55 * * *$ & $(.12)$ & $.98 * * *$ & $(.20)$ & $1.16^{* * *}$ & $(.21)$ \\
\hline Decay effect $\left(\beta_{2}\right)$ & & & $6.87 * *$ & (1.93) & 1.58 & $(.96)$ & $3.13 * *$ & $(1.00)$ \\
\hline $\begin{array}{l}\text { Cumulative learning } \\
\text { effect }\left(\beta_{3}\right)\end{array}$ & & & & & .09 & $(.20)$ & -.15 & $(.08)$ \\
\hline Reinforcement effect $\left(\beta_{4}\right)$ & & & & & $4.57 *$ & (1.93) & $4.68 *$ & $(2.02)$ \\
\hline $\begin{array}{l}\text { Learning effect } \times \\
\text { divorce }\left(\beta_{5}\right)\end{array}$ & & & & & & & $-.59 * * *$ & (.16) \\
\hline $\begin{array}{l}\text { Learning effect } \times \\
\text { adolescence }\left(\beta_{6}\right)\end{array}$ & & & & & & & $.20^{*}$ & $(.10)$ \\
\hline $\begin{array}{l}\text { Decay effect } \times \text { divorce } \\
\left(\beta_{7}\right)\end{array}$ & & & & & & & .05 & $(.28)$ \\
\hline $\begin{array}{l}\text { Decay effect } \times \\
\text { adolescence }\left(\beta_{8}\right)\end{array}$ & & & & & & & $-.63^{*}$ & $(.27)$ \\
\hline Intercept variance level 2 & $4.09 * * *$ & $(.17)$ & $4.16^{* *}$ & $(.17)$ & $4.13 * *$ & $(.17)$ & $4.10^{* * *}$ & $(.17)$ \\
\hline -2log-Likelihood & 37,735 & & 37,684 & & 37,685 & & 37,668 & \\
\hline
\end{tabular}

Significance $* p<.05 ; * * p<.01 ; * * * p<.001$

We expect a negative value for $\beta_{5}$, as the effect of learning will be smaller after a divorce. For $\beta_{6}$, we expect a positive value, as the influence of the criminal acts of fathers will be larger during adolescence. We expect a negative value for $\beta_{7}$, as the decay will be faster in the years following a divorce, while we expect a positive value for $\beta_{8}$, because the decay will be slower during adolescence.

\section{Results}

Model 1 in Table 2 presents the effects of age, sex, parental divorce, a deceased father, and the number of children within the family. It also tests whether the number of criminal convictions of a father (over his entire life course) predicts the chance of a criminal convictions of a child. The results show that both measures used to estimate the age curve are significant. The estimated effects show that the age-conviction curve is asymmetrical. Strikingly, the peak is to the right of the middle (which is at $(39+12) / 2=25.5$ ). 
The peak in the age-crime curve is usually is found in the early twenties, but our finding is likely caused by the official nature of the data used in our research. Many other studies are based on self-report data or police statistics. Model 1 also shows that women are far less likely than men to get convicted in a specific year. In the years after a parental divorce, children have a higher chance of conviction. A deceased father, however, does not lead to an increase in the likelihood of conviction. The number of children within a family is also unrelated to the chance of conviction.

The key finding from Model 1 is the large significant effect of the total number of criminal convictions of the father on the chance of a child's conviction in a year. This supports father's crime hypothesis deduced from static criminological theories (H1). Static theories, however, predict not only the presence of an effect of the number of conviction of the father, they also predict the absence of all learning effects. In Models 2, 3 and 4 we test whether these effects are indeed absent.

Model 2 adds the learning and decay effects. The estimated parameter of the learning effect $\left(\beta_{1}\right)$ is - as hypothesized-positive and significant. In the year a father is convicted for committing crime (and in subsequent years), the chance his child is also convicted increases. The learning hypothesis (H3) is thus supported. The parameter of the decay effect $\left(\beta_{2}\right)$ is positive and significant as well. As the time since a father was last convicted increases, the chances of a child's conviction decrease (after the initial rise due to the learning effect). The decay hypothesis $(\mathrm{H} 4)$ is thus also supported by these findings. The decay parameter $\left(\beta_{2}\right)$ in Model 2 is 6.87 . We can calculate the half-life applying the following equation: $T_{1 / 2}=\beta_{2} \times \ln (2)$. The half-life signifies the number of years that pass until the increased chance of conviction is halved. As such, the half-life gives us insight into the speed of decay. Based of the decay parameter from Model 2, we calculate the halflife to be $6.87 \times \ln (2)=4.76$. This indicates that nearly 5 years are needed for the initial rise in the chance of conviction to decrease by half. Children whose fathers are convicted thus have an increased chance of getting convicted themselves for quite a long time. Whether this increased chance is indeed caused by learning or by some other mechanism remains unclear. We do, however, find evidence for an exponential decay effect, which is typical in learning/forgetting processes.

In Model 3, the learning process is further specified. The decay parameter in this case indicates a reduction in the chance of conviction after father's first criminal conviction. The learning effect after the first criminal conviction expires rapidly, according to the small (insignificant) decay parameter. The associated half-life in this case is $1.58 \times \ln (2)=$ 1.10. After about a year the increased chance of a criminal conviction is already half the original increase. The reinforcement effect, however, indicates that if a father is convicted more often, there is more reinforcement, meaning less rapid decay. When, for example, a father is convicted for the fifth time, the total decay parameter is estimated to be $1.58+\ln (5) \times 4.57=8.94$. The associated half-life is $8.94 \times \ln (2)=6.20$. So, it takes (after father's fifth criminal conviction) more than 6 years before the increased chance of conviction returns halfway between the original chance level and the initial increase. We are not able to test whether the reinforcement effect is in fact caused by a learning mechanism, but both the decay effect and the reinforcement effect display similarities to typical learning/forgetting processes.

The initial learning effect $\left(\beta_{1}\right)$ in Model 3 remains significantly positive, while the parameter for the cumulative learning effect $\left(\beta_{3}\right)$ is insignificant. The chance of a criminal conviction does not rise more as a father is convicted for his second or third time. Our findings therefore do not support the cumulative learning hypothesis. 

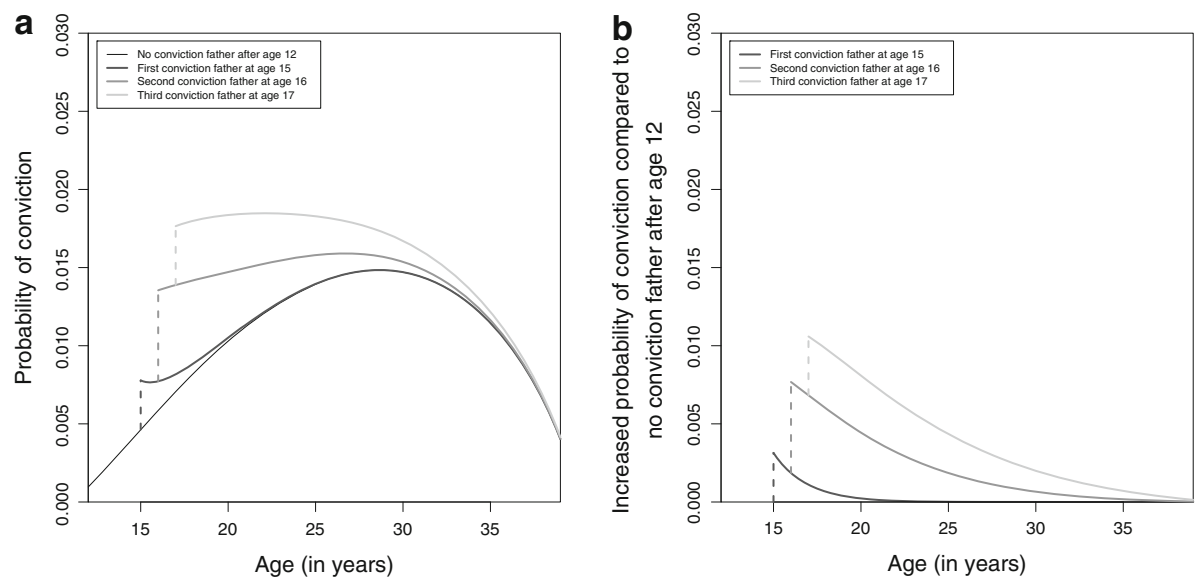

Fig. 1 a Learning effects across the life course. b Decay effects compared to age-conviction-curve

Figure 1 presents the dynamic effects based on Model 3 (all control variables are set to their mean value and only the fixed part of the intercept is used in the calculation). This figure shows (1) the expected criminal conviction career of a child whose father was never convicted after the child reached the age of 12, (2) the expected criminal conviction career of a child whose father was convicted for the first time when the child was 15 years old, (3) the expected criminal conviction career of a child whose father was convicted for the second time when the child was 16 years old, and (4) the expected criminal conviction career of a child whose father was convicted for the third time when the child was 17 years old. We present the complete life courses (1a) and the increased chances compared to the original age-conviction curve (1b). Note that the chance of a criminal conviction rises in the years after a father is convicted. In subsequent years, the chance slowly decreases to its original level. Strikingly, the decay from the first criminal conviction (when the child is 15) occurs much faster than the decay from the second and third criminal conviction (reinforcement effect). This is also supported when we calculate the half-lives. The increased chance after father's first criminal conviction has a half-life of $1.58+\ln (2)=1.09$. The total decay parameter for children of fathers with three criminal convictions is $1.58+\ln (3) \times 4.57=6.06$ and the associated half-life is $6.06 \times \ln (2)=4.20$.

All in all, the results contradict predictions from static theories and offer support for dynamic learning theories. There are indeed effects of the timing of father's criminal convictions. Especially in the years after a father is convicted, the children's chance of conviction is increased. The static hypothesis $(\mathrm{H} 2)$ is thus rejected.

\section{Additional Hypotheses}

A test of our additional hypotheses follows in Model 4. This final model estimates the additional learning and decay effects for adolescents and for those whose parents are divorced. Our expectation was that the learning effect would be larger in adolescence and when the parents were (still) together, while the decay effects would be smaller ( $\mathrm{H} 7$ and $\mathrm{H} 8$ ). Results show that the learning effect $\left(\beta_{5}\right)$ is indeed significantly smaller for people whose parents are divorced than for those whose parents are married. This means that in the year a father is convicted, the chance of conviction for his children increases to a 
smaller extent when the parents are divorced than when parents are (still) together. Although divorce on its own increases the chance for a child to get convicted, divorce moderates the negative effect of a criminal father. In some cases, divorce protects children from exposure to a criminal father, which leads to a reduced chance of conviction. These findings are in line with findings of Jaffee et al. (2003) and Blazei et al. (2008).

The learning effect in adolescence $\left(\beta_{6}\right)$ is significantly positive, which is in line with our expectations. In adolescence, when bonds with parents are relatively strong, the learning effect of a criminal conviction of the father is larger than in adulthood. The decay effect parameter for those with divorced parents $\left(\beta_{7}\right)$ is insignificant. This means that decay occurs at the same speed for those with married parents as for those whose parents are divorced. For adolescents, however, the parameter $\left(\beta_{8}\right)$ is significantly negative. This means that the decay goes faster during adolescence than among adults. This is contrary to our expectations. It could be due to the cumulative number of criminal acts of a father, which in adolescence is of course smaller than in the period after adolescence. We therefore have to reject parts of our divorce hypothesis (H7) and our adolescence hypothesis (H8). We find additional effects of parental divorce and adolescence on the learning effect, but not (at least not in the expected direction) on the degree of decay.

\section{Conclusion}

This paper addressed the question to what extent static and dynamic theories explain the relation between criminal careers of fathers and their children. The study contributes in numerous ways to advance knowledge in the field of intergenerational transmission of crime. First, this is the first study that explicitly looks at the influence of the timing of fathers' criminal convictions on the development of a criminal career of their children. Second, it is the first longitudinal study in which competing explanations regarding intergenerational transmission are explicitly tested. It does so by studying the complete life courses of fathers and children. Finally, this study, using data from the Criminal Career and Life Course Study (CCLS), with complete life courses of almost 7,000 children and their fathers, is the largest study of intergenerational transmission of crime ever executed.

In this study, we tested hypotheses from two paradigms: population heterogeneity and state dependence. We first tested predictions from static theories, which assume that criminal behavior is explained by persistent heterogeneity. The general idea is that only circumstances in early childhood can influence children's criminal behavior. Self-control theory, one of the most important static theories, holds that a relation does exist between the number of criminal acts of a father and those of his children, but this relation would be spurious. Fathers who commit a lot of crime have little self-control and as a result are inadequate child-raisers. Consequently, their children grow up having little self-control and they (will) commit crime as well. The timing of criminal acts of fathers should not matter whatsoever, according to static theories. Second, we introduced predictions from dynamic theories, which state that numerous life course changes (also after early childhood) influence the chance of committing crime. Dynamic theories do also predict an influence of the timing of fathers' criminal acts.

Our findings show support for population heterogeneity. The life courses of children appear to be influenced to a large extent by the total number of criminal convictions of their fathers. In addition, however, there are clear effects of the timing of fathers' criminal convictions. Thus, the process of state dependence is also important in predicting the development of criminal behavior. The results demonstrate that the chance of 
conviction rises in the years in which fathers are convicted for committing their crimes (the learning effect). This effect diminishes with time (the decay effect). With each subsequent criminal act the decay is, however, slower (reinforcement effect). The learning effect is smaller after a parental divorce, when children usually interact less with their father. The learning effect is stronger in adolescence, when bonds with fathers are generally more important than during adulthood. Other studies (e.g., Thornberry et al. 2009; Bijleveld and Wijkman 2009) also suggest the importance of including interaction between parents and their children (e.g., frequence of contact) for understanding the transmission of criminal behavior from one generation to the next. All in all, the results show support for a theory in which both population heterogeneity and state dependence processes are incorporated.

Although hypotheses derived from static theories are partly corroborated in the present study, as in earlier studies using CCLS data (e.g., Van de Rakt et al. 2008), the claim that life course circumstances do not influence the development of criminal behavior has to be rejected. Previous authors point out that the static viewpoint on the development of criminal behavior is a simplified rendering at best (Blokland 2005; Tittle et al. 2003).

As this study makes use of official data only, we have access to just a few control variables. We were not able to test the mechanisms of the proposed learning/forgetting process directly. Ideally, we would like to take much more control and process variables into account. Information about contact frequency of fathers and children or parenting styles would have made our research much stronger. Also, differences in social status between criminal and noncriminal fathers would probably explain part of the relation. Factors such as education and residential neighborhood are likely to influence the relations as well. Future research should be able to provide more definite answers as to the relative importance of these factors.

Another disadvantage of the official conviction data is that they lead to the underestimation of the true number of crimes committed. Of course, many crimes are not recorded by the police. As long as this underestimation is nonselective, it does not affect the findings in this study. However, the chance of getting caught by the police is probably higher for some criminal fathers and their children because they are more extensively monitored by the police. Previous research (Hagan and Palloni 1990) already indicated that official data offer a selective underestimation. In that case, the level of intergenerational transmission found in this paper could be overestimated. A great advantage of our official data, however, is that we avoid social desirability and memory problems, because we do not rely on self-report data. Furthermore, these official data allow us to also study more serious forms of criminal behavior which are seldom examined in research that is based on self-reports.

Although this study provides valuable insights, more research is needed on alternative explanations for the relation between criminal convictions of fathers and those of their children. Future research, for example, should focus on the influence of imprisonment on criminal life courses.

Acknowledgments This study was made possible by a grant from the Netherlands Organization of Scientific Research (NWO, 400-05-052).

Open Access This article is distributed under the terms of the Creative Commons Attribution Noncommercial License which permits any noncommercial use, distribution, and reproduction in any medium, provided the original author(s) and source are credited. 


\section{References}

Akers R, Jensen G (2003) Social learning theory and the explanation of crime. A guide for the new century. Transaction Publishers, New Brunswick

Bijleveld C, Farrington D (2009) The importance of studies of intergenerational transmission of antisocial behavior. Crim Behav Ment Health 19:77-79

Bijleveld C, Wijkman M (2009) Intergenerational continuity in convictions: a five-generation study. Crim Behav Ment Health 19:142-155

Blazei R, Iacono W, McGue M (2008) Father-child transmission of antisocial behavior: the moderating role of father's presence in the home. J Am Acad Child Adolesc Psychiatry 47:406-415

Blokland A (2005) Crime over the life span: trajectories of criminal behavior in Dutch offenders. Alblasserdam, Haveka

Blokland A, Nieuwbeerta P (2005) The effects of life circumstances on longitudinal trajectories of offending. Criminology 43:1203-1240

Blossfeld H-P, Huinink J (1991) Human capital investments or norms of role transition? How women's schooling and career affect the process of family formation. Am J Sociol 97:143-168

Bushway S, Brame R, Paternoster R (1999) Assessing stability and change in criminal offending: a comparison of random effects, semiparametric and fixed effects modeling strategies. J Quant Criminol $15: 23-61$

Ebbinghaus H (1913) Memory: a contribution to experimental psychology. Columbia University, New York

Farrington D, Lambert S, West D (1998) Criminal careers of two generations of family members in the Cambridge study in delinquent development. Stud Crime Crime Prev 7:85-106

Farrington D, Jolliffe D, Loeber R, Stouthamer-Loeber M, Kalb L (2001) The concentration of offenders in families, and family criminality in the prediction of boy's delinquency. J Adolesc 24:579-596

Fischer T (2004) Parental divorce, conflict and resources: the effects on children's behavior problems, socioeconomic attainment, and transitions in the demographic career. Ponsen \& Looijen, Wageningen

Fischer T, De Graaf P, Kalmijn M (2005) Friendly and antagonistic contact between former spouses after divorce: patterns and determinants. J Fam Issues 26:1131-1163

Gorman-Smith D, Tolan P, Loeber R, Henry D (1998) Relation of family problems to patterns of delinquent involvement among urban youth. J Abnorm Child Psychol 26:319-333

Gottfredson M, Hirschi T (1990) A general theory of crime. Stanford University Press, Stanford

Hagan J, Palloni A (1990) The social reproduction of a criminal class in working-class London, circa 19501980. Am J Sociol 96:265-299

Harper C, McLanahan S (2004) Fathers absence and youth incarceration. J Res Adolesc 14:369-397

Jaffee S, Moffitt T, Caspi A, Taylor A (2003) Life with (or without) father: the benefits of living with two biological parents depend on the father's antisocial behavior. Child Dev 74:109-126

Kaplan H, Tolle G (2006) The cycle of deviant behavior: investigating intergenerational parallelism. Springer, New York

Laub J, Sampson R (2003) Shared beginnings, divergent lives: delinquent boys to age 70. Harvard University Press, Cambridge

McLanahan S, Sandefur G (1994) Growing up with a single parent: what hurts, what helps. Harvard University Press, Cambridge

Moffitt T (1993) Adolescence-limited and life-course-persistent antisocial behavior: a developmental taxonomy. Psychol Rev 100:674-701

Nagin D, Paternoster R (1991) On the relationship of past to future criminal participation in delinquency. Criminology 29:163-189

Nagin D, Paternoster R (2000) Population heterogeneity and state dependence: state of the evidence and directions for future research. J Quant Criminol 16:117-144

Nieuwbeerta P, Blokland A (2003) Criminal careers of adult Dutch offenders (codebook and documentation). NSCR, Leiden

Paternoster R, Dean C, Piquero A, Mazerolle P, Brame R (1997) Generality, continuity and change in offending. J Quant Criminol 13:231-266

Piquero A, Farrington D, Blumstein A (2003) The criminal career paradigm. Crime Justice 30:359-506

Rowe D, Farrington D (1997) The familial transmission of criminal convictions. Criminology 35:177-202

Sampson R, Laub J (1990) Crime and deviance over the life course: the salience of adult social bonds. Am Sociol Rev 55:609-627

Sampson R, Laub J (1993) Crime in the making: pathways and turning points through life. Harvard University Press, Cambridge

Smith C, Farrington D (2004) Continuities in antisocial behavior and parenting across three generations. J Child Psychol Psychiatry 45:230-247 
Sutherland E, Cressey D, Luckenbill D (1992) Principles of criminology. General Hall, New York

Thornberry T (2005) Explaining multiple patterns of offending across the life course and across generations. Ann Am Acad Pol Soc Sci 602:156-195

Thornberry T, Freeman-Gallant A, Lizotte A, Krohn M, Smith C (2003) Linked lives: the intergenerational transmission of antisocial behavior. J Abnorm Child Psychol 31:171-184

Thornberry T, Freeman-Gallant A, Lovegrove P (2009) Intergenerational linkages in antisocial behaviour. Crim Behav Ment Health 19:80-93

Tittle C, Ward D, Grasmick H (2003) Self-control and crime/deviance: cognitive versus behavioral measures. Criminology 19:333-365

Van de Rakt M, Nieuwbeerta P (2005) Criminal careers of adult Dutch offenders and their children (codebook and documentation). NSCR, Leiden

Van de Rakt M, Nieuwbeerta P, de Graaf ND (2006) Zo vader zo zoon? De intergenerationele overdracht van crimineel gedrag. Tijdschrift voor Criminologie 48:345-360

Van de Rakt M, Nieuwbeerta P, De Graaf ND (2008) Like father, like son? The relationships between conviction trajectories of fathers and their sons and daughters. Br J Criminol 48:538-556

Van de Rakt M, Nieuwbeerta P, Apel R (2009) The association of criminal convictions between family members: effects of siblings, fathers and mothers. Crim Behav Ment Health 19:94-108

Wilson J, Hernstein R (1985) Crime and human nature. Simon \& Schuster, New York

Wixted J, Ebbesen E (1991) On the form of forgetting. Psychol Sci 2:409-415 